\title{
Saving, Risk Sharing and Preferences for Risk
}

\author{
Maurizio Mazzocco* \\ Revised Version, March 2004
}

\begin{abstract}
Saving decisions are made jointly by household members who generally earn risky incomes. Consequently, to interpret saving patterns it is crucial to analyze the relationship between intrahousehold risk sharing and intertemporal choices. To that end in this paper the household is characterized as a group of agents with possibly heterogeneous preferences making efficient decisions. Two results are obtained. First, it is shown that risk sharing can increase the amount saved by the household. Second, I find that an increase in risk aversion and prudence of an individual member can reduce household risk aversion and prudence. These results are consistent with the empirical evidence collected using the HRS.
\end{abstract}

\section{Introduction}

An important feature of household saving decisions is the ability of individual members to share risk among them. With few exceptions, theoretical and empirical studies characterize household saving as if a single agent were making the decision. Under this assumption, the risk sharing component of household saving is largely ignored. This paper is one of the first attempts to analyze the effect of risk sharing on saving by characterizing the household as a group of agents making efficient decisions.

To evaluate the relevance of risk sharing in understanding saving behavior, consider a household in which the two members have different preferences, earn risky incomes and can share risk between

*I am very grateful to Orazio Attanasio, Pierre André Chiappori, Lucas Davis, Christian Gollier, James Heckman, Igal Hendel, John Kennan, Lars Lefgren, Annamaria Lusardi, Bernard Salanie, Robert Townsend, the editor and two anonymous referees for their insight and suggestions. I would also like to thank seminar participants for helpful comments. Errors are mine. 
them. How does risk sharing affect household saving? Consider a second household which is identical to the previous one except that the husband's willingness to save for precautionary reasons is greater than the willingness of the husband in the first household at any given level of resources. Is saving in the second household larger? At first glance the answers seem straightforward. Under standard assumptions risk sharing should always reduce saving and an increase in the willingness to save of one agent should always increase household saving. However, this intuition is not complete. To see this, it is helpful to divide intra-household risk sharing into two parts. First, individual members pool their earnings and consequently eliminate part of the uncertainty faced by the household. Under convex marginal utilities, income pooling always has the intuitive effect of reducing saving. Second, household members insure each other by allocating pooled income according to individual risk preferences and decision power. The main contribution of this paper is to show that the insurance component of risk sharing can have two counterintuitive results. First, it can raise household saving. Second, an increase in prudence of one agent can reduce household prudence and hence household saving.

The first part of the paper presents empirical evidence which suggests that risk sharing is an important feature of saving decisions. The Health and Retirement Study (HRS) gathers information on the willingness to gamble over lifetime income. Using these data each respondent is assigned to one of four possible risk preference categories. Even with this limited number of categories, about 50 percent of couples report that the wife's risk preferences differ from the husband's. This indicates that the impact of risk sharing on household intertemporal behavior is not limited to income pooling. To further explore this hypothesis, the data on risk preferences are used jointly with the HRS data on saving to compare the saving pattern of couples with the saving pattern of singles. Average saving of singles increases with individual risk aversion and prudence. However, average saving of couples is a U-shaped function of the husband's risk aversion and prudence.

This paper attempts to explain the distinct saving behavior of couples using an intertemporal framework with income uncertainty and the following two features: (i) household members are characterized by individual preferences; (ii) household decisions are efficient. Two results are obtained. First, it is shown that risk sharing has the intuitive effect of always reducing saving if and only if individual members have identical discount factors, identical beliefs and Harmonic Absolute Risk 
Aversion (HARA) preferences with identical curvature parameters. ${ }^{1}$ Second, under the assumption of HARA preferences, it is shown that an increase in risk aversion and prudence of an individual member can reduce household risk aversion and prudence.

To provide the intuition underlying the first result note that the optimal allocation of pooled resources shifts the individual members along their Engel curves so as to enhance efficiency. If the household members have identical decision power, efficiency is maximized by allocating most of the risk to the least risk averse agent. In particular, for any adverse realization of household income, a larger portion of resources is transferred to the most risk averse agent. For any good realization of household income, the least risk averse agent receives the majority of income. As an example, consider a household in which the two members have identical income processes, identical decision power and linear Engel curves. In addition, suppose that the Engel curves of the least risk averse agent are steeper. Then, in any adverse state of nature, the optimal transfer has a negative effect on household consumption and a positive effect on saving. In any good state of nature, the efficient allocation of resources has the opposite effect. Hence, risk sharing increases saving if the transfers in the adverse states dominate the transfers in the good states. This suggests that risk sharing always has the intuitive effect of reducing saving if and only if household aggregate behavior is independent of the insurance component of risk sharing. This condition is fulfilled if and only if under efficiency the individual Engel curves are linear with identical slopes. Only households characterized by identical discount factors, identical beliefs and HARA preferences with identical curvature parameters have Engel curves with these properties.

The findings of this paper have one main implication. Observe that the framework traditionally used to analyze saving assumes that the household behaves as a single agent. This restriction is equivalent to the assumption that the optimal allocation of pooled resources has no effect on saving behavior. Therefore, the results of this work imply that the predictions of the standard framework may be used to interpret saving patterns only under assumptions which guarantee that household aggregate behavior is independent of the insurance component of risk sharing. An important consequence is that any policy recommendation formulated using the standard unitary framework generally ignores the impact of the policy on the efficient allocation of risk across household members.

\footnotetext{
${ }^{1}$ Two agents have HARA preferences with identical curvature parameters if $u^{i \prime}(c)=\left(a_{i}+c\right)^{-\gamma}$.
} 
To be able to evaluate the full effect of a policy on saving decisions, it is necessary to estimate the intra-household allocation of resources jointly with individual risk preferences.

The results of this paper may also help explain the mixed evidence reported in the empirical literature on precautionary saving. In most of these papers, the significance of the precautionary motive is determined using the uncertainty intrinsic in household income. Since household income captures only the income pooling component of risk sharing, the findings should vary with the magnitude and the direction of the insurance component of risk sharing characterizing the group of households used in the estimation.

Saving decisions have been analyzed extensively in the past, but mostly under the assumption that a unique utility function can be used to represent the household. ${ }^{2}$ The main exception is the paper by Browning (2000), in which a non-cooperative model of household decisions with heterogeneous discount factors but otherwise identical agents and no income uncertainty is employed to analyze the effect of differences in life expectancy between spouses on saving. The present paper is also related to the literature on the collective representation of household behavior. Specifically, the framework proposed in this paper generalizes the static collective model introduced by Pierre-André Chiappori $(1988,1992)$ to an intertemporal environment with uncertainty. Finally, the present work is linked to the literature on group decisions. The main example is the work by Christian Gollier (2001a). He examines the relationship between individual risk preferences and the risk preferences of the representative agent to determine how wealth inequality affects the equity premium and the interest rate. The present paper is, however, one of the first attempts to characterize the saving behavior of a group of heterogeneous agents.

The remainder of the paper is organized as follows. In section 2, some empirical evidence on household saving and individual risk preferences is presented. In section 3, the intertemporal collective model is introduced jointly with a numerical example. In section 4 , the impact of risk sharing on household saving is examined. In section 5, household risk aversion and prudence are introduced and their relationship with individual risk preferences is analyzed. Section 6 concludes.

\footnotetext{
${ }^{2}$ See Martin Browning and Annamaria Lusardi (1996) for a comprehensive survey.
} 


\section{Empirical Motivations}

The literature on household intertemporal behavior has traditionally divided saving into two main components: precautionary saving and consumption smoothing. If future income is uncertain, consumers accumulate wealth to face adverse shocks to their earnings. Miles S. Kimball (1990) shows that the precautionary motive rises with the convexity of marginal utility, which is measured by the coefficient of absolute prudence, $-u^{\prime \prime \prime}(C) / u^{\prime \prime}(C)$. If preferences are concave, it is valuable to smooth consumption over time, accumulating and reducing wealth. The strength of the consumption smoothing motive is measured by the degree of concavity of the utility function, which is characterized by the coefficient of absolute risk aversion, $-u^{\prime \prime}(C) / u^{\prime}(C)$, introduced by John W. Pratt (1964). If households behave as single agents, saving of singles and saving of couples should have identical features. In particular, under standard assumptions, saving should be an increasing function of absolute prudence. Moreover, saving should rise with absolute risk aversion if the gross interest rate multiplied by the discount factor is smaller than one.

The HRS represents a good opportunity to analyze household intertemporal behavior, since it collects simultaneously information on saving and individual preferences for risk. These data are useful for two related reasons. First, they enable one to determine how spouses are matched in terms of risk preferences. Second, the data can be used to establish the relationship between individual risk preferences and household saving for couples and separately for singles. The survey elicits risk preferences by asking the respondents two questions related to their willingness to gamble over lifetime income. The questions are included in Wave I of the survey, which was administered in 1992, and are asked to the head of the household and, if present, to the spouse. The two questions enable the investigator to divide the respondents into four distinct categories. These categories can be ranked in terms of risk aversion and prudence without having to assume a particular functional form for the respondent's utility function. The two questions can be described as follows. Suppose that the respondent has the opportunity to choose between the current job, which guarantees the current income of $y$ for the rest of her life, and a new and equally good job with 50-50 chance of doubling permanent income and a 50-50 chance that permanent income will be cut by a fraction $\theta$. In the first question $\theta$ is set equal to one third. If the individual accepts the gamble, in the second question $\theta$ is raised to one half. If the respondent rejects the first gamble, in the second question $\theta$ is reduced to 
Table 1: Risk Preference Categories.

\begin{tabular}{|l|c|c|}
\hline \hline Risk Preference Category & Deg. of Risk Aversion-Prudence & Respondent Type \\
\hline Category I & lowest & accept one-third, accept one half \\
\hline Category II & low & accept one-third, reject one-half \\
\hline Category III & high & reject one-third, accept one-fifth \\
\hline Category IV & highest & reject one-third and one-fifth \\
\hline
\end{tabular}

Table 2: Matching of Spouses Based on Risk Preferences.

\begin{tabular}{|l|r|r|r|r|r|}
\hline \hline & \multicolumn{5}{|c|}{ Wife's Risk Preferences } \\
\hline Husband's Risk Preferences & Cat. I & Cat. II & Cat. III & Cat. IV & Total \\
\hline Cat. I & 92 & 65 & 57 & 272 & 486 \\
\hline Cat. II & 43 & 70 & 49 & 223 & 385 \\
\hline Cat. III & 52 & 51 & 82 & 239 & 424 \\
\hline Cat. IV & 216 & 214 & 285 & 1657 & 2372 \\
\hline Total & 403 & 400 & 473 & 2391 & 3667 \\
\hline
\end{tabular}

one fifth. It is important to remark that the respondent's choice is affected by her willingness to face the additional uncertainty implicit in the new job. This willingness depends on individual prudence directly and through the amount of available saving. Consequently, the two questions provide joint information on risk aversion and prudence. The four categories are illustrated in Table $1 .^{3}$

It is now possible to describe the relationship between the wife's and the husband's risk preferences. According to Table 2, even with only four categories of risk preferences, about 50 percent of couples report that the wife's risk aversion and prudence differ from the husband's. This evidence represents a first indication that the saving decisions of couples are generally more complex than the saving decisions of singles.

The HRS also contains detailed information on household saving. Specifically, using the panel structure of the HRS, saving can be computed as the difference in financial wealth between the second and first wave, where financial wealth is defined as total wealth minus home equity, the value of vehicles and real estate. ${ }^{4}$ The relationship between saving and individual risk preferences can then be determined. Table 3 reports the average value of saving as a function of risk preferences for five different groups of households: (i) couples in which the wife belongs to the highest category of risk aversion and prudence; (ii) couples in which the wife belongs to category IV and to the labor force

\footnotetext{
${ }^{3}$ For the exact wording of the questions and a detailed description of the four categories see the insightful paper by Robert B. Barsky et al. (1997). For a thorough discussion of the HRS see Thomas F. Juster and Richard Suzman (1995) and Juster and James P. Smith (1997).

${ }^{4}$ Durables are excluded to focus on assets that do not provide utility to the owner.
} 
Table 3: Average Financial Saving as a Function of Husband's Risk Preferences.

\begin{tabular}{lccccc}
\hline \hline & $\begin{array}{c}\text { Couples, } \\
\text { Wife=IV }\end{array}$ & $\begin{array}{c}\text { Couples, Wife=IV } \\
\text { in Labor Force }\end{array}$ & $\begin{array}{c}\text { Couples, Wife=IV } \\
\text { not in Labor Force }\end{array}$ & Singles & $\begin{array}{c}\text { Singles, } \\
\text { No Retirees }\end{array}$ \\
\hline \hline Category I & 29569.9 & 45147.82 & -17442.14 & -8458.237 & -9708.2 \\
& {$[9438.1]$} & {$[10494.52]$} & {$[20847.3]$} & {$[5554.6]$} & {$[6011.9]$} \\
Category II & 8929.6 & 5705.7 & 22931.7 & 6575.0 & 5636.4 \\
& {$[10826.2]$} & {$[11571.7]$} & {$[27578.4]$} & {$[6357.02]$} & {$[7143.2]$} \\
Category III & 16557.5 & 12028.3 & 32409.9 & 11108.7 & 12618.7 \\
& {$[10061.0]$} & {$[10993.8]$} & {$[23518.9]$} & {$[6445.2]$} & {$[7143.2]$} \\
Category IV & 18731.8 & 18097.3 & 20643.0 & 8712.1 & 7883.7 \\
& {$[3890.7]$} & {$[4327.3]$} & {$[8587.9]$} & {$[2639.9]$} & {$[2905.1]$} \\
\hline N. Households & 1918 & 1456 & 462 & 1671 & 1447 \\
\hline \hline
\end{tabular}

Note: Standard errors are in brackets.

in the first or second wave; (iii) couples in which the wife belongs to category IV but she is out of the labor force in the first and second wave; (iv) households with only one adult; (v) households with only one adult who is not retired. ${ }^{5}$ Before analyzing the results, three caveats of the approach should be discussed. First, measures of saving calculated as the first difference of wealth are generally very noisy. Consequently, the results may be affected by measurement errors. ${ }^{6}$ Second, to reduce the number of missing values, the HRS has used unfolding brackets in all instances in which the respondent refused to give a specific value for a particular component of wealth. Unfortunately, different brackets have been used in the two waves. To address this problem, a household is dropped from the sample if brackets have been employed in both first and second wave for any one of the wealth components used to compute saving. ${ }^{7}$ Third, risk preferences are only one of the factors determining saving. In the empirical exercise I do not control for additional variables that may affect intertemporal decisions. Consequently, the results represent a simple description of the link between saving and risk preferences. ${ }^{8}$

\footnotetext{
${ }^{5} \mathrm{~A}$ wife is considered out of the labor force if she is retired or a housewife. Households with one adult include never married, separated, divorced respondents and widows.

${ }^{6}$ To reduce the impact of measurement errors, outliers are dropped from the sample. An observation is considered an outlier if it satisfies the following two conditions: the absolute value of saving is larger than one million dollars and financial wealth more than doubled or shrank by more than half between the two years.

${ }^{7}$ Smith (1995) finds that the non-response which triggers the use of the brackets is not random. Consequently, eliminating all households which make use of brackets in both waves represents only a partial solution to the problem.

${ }^{8}$ In Maurizio Mazzocco (2003a), saving is regressed on a set of dummies corresponding to the risk preference categories, after controlling for age, education, children, income, initial wealth and selection into marriage. The results are consistent with the findings of this section.
} 
In Table 3, saving of singles generally increases with the degree of risk aversion and prudence. ${ }^{9}$ Saving of couples in which the wife belongs to category IV is a U-shaped function of individual risk preferences. The difference in saving patterns seems to be driven by the group of households in which the wife belongs to the labor force. Indeed, saving of couples in which the wife is out of the labor force has the same shape as saving of singles. These results represent an additional indication that saving decisions of households with more than one decision maker are generally different from saving decisions of single agents. Moreover, the results suggest that the status of household members is important in understanding household intertemporal behavior.

\section{The Intertemporal Collective Model}

To analyze the saving decisions of couples, consider a household living for two periods and composed of two agents each one endowed with an exogenous income process. ${ }^{10}$ In the first period, member $i$ 's income is known and equal to $y^{i}$. In the second period, individual income is stochastic and will be denoted with $\tilde{y}^{i}(\omega)$, where $\omega$ is one of the potential states of nature. In each period, member $i$ consumes a private composite good. Let $c^{i}$ and $\tilde{c}^{i}(\omega)$ be consumption in the first and second period. The household can save using a risk-free asset. Denote with $s$ and $R$ the amount of wealth invested in the risk-free asset and its gross return. Each household member is characterized by individual preferences, which are assumed to be separable over time and across states of nature. The corresponding utility function, $u_{i}$, is assumed to be increasing, concave and three times continuously differentiable. Following Christopher D. Carroll and Kimball (1996), throughout the paper the income processes are required to be permissible, i.e. the income processes are such that consumption remains within the domain over which the considered utility functions are defined. It is assumed that the household decision process is efficient. This is the main assumption of the paper and it requires that household members can fully commit to future allocations of resources. ${ }^{11}$ Let $\beta_{i}$,

\footnotetext{
${ }^{9}$ The small decline in saving for category IV disappears after controlling for demographics, income and wealth. It is also important to remark that the sample size of category IV is about five times the sample size of the other categories.

${ }^{10}$ It is straightforward to generalize the results obtained in this paper to a household with $n$ agents. To isolate the effect of risk sharing, household formation is not considered.

${ }^{11}$ Under efficiency agents will only save jointly. The assumption that household members cooperate is well established in the literature (see Gary S. Becker (1991) and Chiappori (1992)). Orazio P. Attanasio and Mazzocco (2003), Shelly Lundberg et al. (forthcoming) and Mazzocco (2003b) analyze household behavior with limited commitment.
} 
$F_{i}$ and $E_{i}$ be the discount factor of member $i$, the probability measure describing her beliefs and the expected value calculated with respect to these beliefs. Household decisions can then be determined by solving the following Pareto problem: ${ }^{12}$

$$
\begin{gathered}
\max _{\left\{c^{i}, \tilde{c}^{i}, s\right\}_{i=1,2}} \sum_{i=1}^{2} \mu_{i}\left\{u_{i}\left(c^{i}\right)+\beta_{i} E_{i}\left[u_{i}\left(\tilde{c}^{i}\right)\right]\right\} \\
\sum_{i=1}^{2} c^{i}+s \leq \sum_{i=1}^{2} y^{i} \\
\sum_{i=1}^{2} \tilde{c}^{i} \leq \sum_{i=1}^{2} \tilde{y}^{i}+R s \text { for all } \omega,
\end{gathered}
$$

where $\mu_{i}$ is member $i$ 's Pareto weight. In this framework, the welfare of individual agents is increased if they choose to live in a household for two reasons. First, they can share between them the uncertainty implicit in the income processes. Second, since the model developed in this section allows for the additive form of altruism, the consumption of one agent may increase the spouse's welfare. Moreover, even if a public good is not explicitly considered, the results obtained using this framework can be interpreted as the results of a model in which preferences are strongly separable between private and public consumption.

To evaluate whether the proposed representation of household intertemporal behavior may help in understanding the complexity of saving decisions of couples, a realistic numerical example will be first considered. The aim of the example is twofold. First, it will clarify the effect of risk sharing on saving. Second, it will illustrate the relationship between saving and individual risk preferences. Consider a group of households each composed of two agents with Constant Relative Risk Aversion (CRRA) preferences. ${ }^{13}$ Under this assumption on preferences, Barsky et al. (1997) use the HRS to estimate individual relative risk aversion and prudence conditional on belonging to one of the four categories described in the previous section. They find that relative prudence for category I, II, III and IV is equal to, respectively, 4.8, 6.7, 8.2 and 16.7. To be consistent with these estimates, in the numerical example it is assumed that the wife's relative prudence is constant across households and equal to 16.7, whereas the husband's relative prudence varies from 4.8 to 16.7. Individual income in

\footnotetext{
${ }^{12}$ To simplify the notation the dependence on the state of nature will be suppressed.

${ }^{13} \mathrm{~A}$ household member has CRRA preferences if $u(c)=c^{1-\gamma} /(1-\gamma)$, where $\gamma$ represents relative risk aversion and relative prudence minus one.
} 
Figure 1: Total Household Saving as a Function of Husband's Prudence

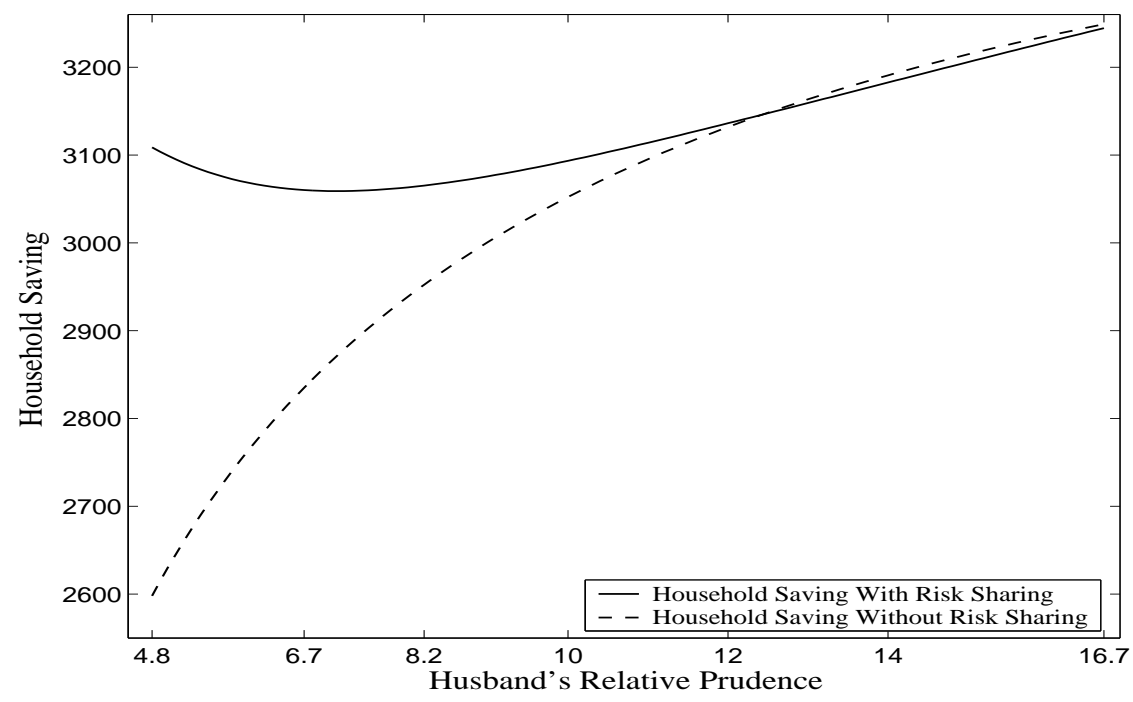

the first period is equal to 15,000 dollars for the wife and 11,000 dollars for the husband. The second period is characterized by three states of nature, which can prevail with identical probability. The wife's income in the three states of nature is equal to 24,000, 12,000 and 15,000 dollars, whereas the husband's income is equal to $36,000,6,000$ and 9,000 dollars. It is assumed that $\beta=R=1$, which implies that the example focuses on the effect of risk sharing on precautionary saving. To fully characterize efficient risk sharing, it is crucial to determine the threshold below which realizations of household income are perceived as adverse realizations. The threshold, which determines the direction of the transfers between the two agents, is set equal to the median of household income in 1992 for the sample of couples, which is 48,000 dollars. ${ }^{14}$ Using this example household saving is first computed as the solution of the intertemporal collective model, i.e. allowing individual members to share risk efficiently. Household saving is then determined as the sum of individual saving under the assumption that the two spouses can only consume their own resources. Figure 1 reports saving as a function of the husband's prudence. For the majority of households, efficient risk sharing has the counterintuitive effect of increasing saving. Moreover, if individual members are allowed to share risk efficiently, household saving is a U-shaped function of individual prudence.

The remainder of the paper is devoted to placing in a more general context the counterintuitive results obtained in this section and to showing that they are the outcome of the same feature of

\footnotetext{
${ }^{14}$ Section III will clarify how the threshold affects household intertemporal behavior.
} 
household behavior.

\section{Efficient Risk Sharing and Household Saving}

The numerical example discussed in the previous section suggests that efficient risk sharing can increase household saving. The aim of this section is to evaluate the generality of this result and hence its empirical relevance in understanding saving decisions.

To determine the effect of risk sharing on saving it is useful to reformulate the household decision process using a two-stage framework. In the first stage, the household decides the optimal distribution of total income between the two agents in each period and state of nature. In the second stage, given the allocation of total resources, each agent chooses individual consumption and saving. Formally, let $\left\{\rho^{i}, \tilde{\rho}^{i}\right\}_{i=1,2}$ be an arbitrary distribution of available income between the two agents in each period and state of nature. Given $\left\{\rho^{i}, \tilde{\rho}^{i}\right\}_{i=1,2}$, in the second stage member $i$ solves the following problem:

$$
\begin{gathered}
V_{i}\left(\left\{\rho^{i}, \tilde{\rho}^{i}\right\}\right)=\max _{c^{i}, \tilde{c}^{i}, s^{i}} u_{i}\left(c^{i}\right)+\beta_{i} E_{i}\left[u_{i}\left(\tilde{c}^{i}\right)\right] \\
\text { s.t. } c^{i}+s^{i} \leq \rho^{i} \\
\tilde{c}^{i} \leq \tilde{\rho}^{i}+R s^{i} \text { for all } \omega .
\end{gathered}
$$

In the first stage, the household determines the optimal allocation of total income as a solution of the following problem:

$$
\begin{gathered}
\max _{\left\{\rho^{i}, \tilde{\rho}^{i}\right\}_{i=1,2}} \sum_{i=1}^{2} \mu_{i} V_{i}\left(\left\{\rho^{i}, \tilde{\rho}^{i}\right\}\right) \\
\text { s.t. } \sum_{i=1}^{2} \rho^{i} \leq \sum_{i=1}^{2} y^{i} \\
\sum_{i=1}^{2} \tilde{\rho}^{i} \leq \sum_{i=1}^{2} \tilde{y}^{i} \text { for all } \omega .
\end{gathered}
$$

Using the first and second welfare theorems, it is straightforward to show that the solution of the two-stage formulation is equivalent to the solution of the intertemporal collective model. The twostage framework clarifies that risk sharing can be divided into two parts. First, individual members 
pool their incomes and hence eliminate the idiosyncratic uncertainty implicit in their earnings. This component of risk sharing is captured by the feasibility conditions of the first stage, which depend exclusively on total household income. Second, the pooled resources are optimally allocated according to individual risk preferences and decision power. Specifically, let $\bar{C}$ be the threshold below which an income realization is perceived as adverse. For identical Pareto weights, if an income realization is below $\bar{C}$, the most risk averse agent receives a larger fraction of household income. If the income realization is above $\bar{C}$, the household transfers the majority of household income to the least risk averse member as a compensation for the insurance provided. If the Pareto weights are different, the allocation that provides the optimal insurance is adjusted by transferring additional resources to the agent with higher decision power. The insurance component of risk sharing is summarized by the sharing rule $\left\{\rho^{i}, \tilde{\rho}^{i}\right\}_{i=1,2}$.

It is now possible to verify the effect of efficient risk sharing on saving. To that end, household saving is first computed allowing individual members to share risk efficiently, i.e. as a solution of the intertemporal collective model. Household saving is then determined under the assumption that the two agents cannot share risk. Specifically, member $i$ 's saving is the solution of the following standard problem:

$$
\begin{gathered}
\max _{c^{i}, \tilde{c}^{i}, s^{i}} u_{i}\left(c^{i}\right)+\beta_{i} E_{i}\left[u_{i}\left(\tilde{c}^{i}\right)\right] \\
\text { s.t. } c^{i}+s^{i}=y^{i} \\
\tilde{c}^{i}=\tilde{y}^{i}+R s^{i} \text { for all } \omega .
\end{gathered}
$$

Finally, the two outcomes are compared.

Let an ISHARA household be a household in which the two members have identical discount factors, identical beliefs and HARA preferences with identical curvature parameters. The following theorem is the main result of the paper and it shows that efficient risk sharing has always the intuitive effect of reducing saving if and only if the household belongs to the ISHARA class. For any other household, it is always possible to find income processes and decision power such that risk sharing increases saving.

Theorem 1 Efficient risk sharing reduces saving for any income process and decision power if and only if the household belongs to the ISHARA class. 
Proof. In the appendix.

To illustrate the idea behind Theorem 1, it is useful to divide risk sharing into its two components. Under convex marginal utilities, income pooling always reduces saving. The insurance component of risk sharing always reduces saving if and only if two conditions are jointly satisfied. First, under efficiency, the income expansion paths of each individual member are linear. ${ }^{15}$ Otherwise it is always possible to find households for which the allocation of total income interacts with the non-linearities so as to increase saving. Second, under efficiency, the individual Engel curves have the same slope. Otherwise it is always possible to find households that allocate most of the resources to the spouse with the less steep income expansion paths. Only the ISHARA class satisfies both restrictions. ${ }^{16}$

Some remarks are in order. First, Theorem 1 clarifies that risk sharing can increase saving even if the household members have identical preferences, discount factors and beliefs. Second, for ISHARA households efficient risk sharing always reduces saving because the insurance component of risk sharing has no effect on household aggregate behavior. The model traditionally used to analyze precautionary saving assumes that a unique utility function can be assigned to the household. Under this restriction, the insurance component of risk sharing has no effect on saving. Consequently, the standard unitary framework has the same predictions as the intertemporal collective model only if the household belongs to the ISHARA class. There are two main examples of households that belong to the ISHARA class. In both instances beliefs and discount factors are identical across agents. In the first case, household members have Constant Absolute Risk Aversion (CARA) utilities. ${ }^{17}$ In the second case, the two agents are characterized by identical CRRA utilities. Third, Theorem 1 can be used to rationalize the U-shaped saving function obtained in the numerical example. According to Theorem 1 for any set of individual preferences outside the ISHARA class, it is always possible to find income processes such that the insurance component of risk sharing increases saving. Moreover, it can be shown that the set of income processes with this property expands if the difference in individual risk preferences is increased. In the numerical example the income pro-

\footnotetext{
${ }^{15}$ The terms income expansion path and Engel curve will be used interchangeably.

${ }^{16}$ The ISHARA class is also examined in John W. Pratt and Richard J. Zeckhauser (1989). Specifically, using a static model with uncertainty they show that any group outside the ISHARA class can accept lotteries over individually unacceptable lotteries.

${ }^{17}$ A CARA utility function can be obtained by taking the limit of a HARA utility function as the curvature parameter tends to $-\infty$. Consequently, all CARA utility functions have identical curvature parameters.
} 
cesses and the wife's risk preferences are identical across households, whereas the husband's risk preferences vary. Consequently, income pooling has the same effect on the saving behavior of all households. The insurance component of risk sharing, however, differs across households. In particular, the individual income processes used in the numerical example belong to the set of incomes for which the insurance effect increases saving if the difference between the husband's and the wife's curvature parameter is larger than 9.6. As a final remark note that households in which one agent has all the decision power behave as households with only one decision maker. This is consistent with the empirical evidence reported in Table 3 which suggests that the status of individual members affects saving.

It is instructive to analyze the effect of risk sharing on precautionary saving and separately on consumption smoothing. To that end it is important to note that the individual Engel curves contain all the information related to efficient risk sharing. To see this suppose that in the second period $m$ states of nature can prevail, with $m$ finite. Then the budget constraints of the second stage of the intertemporal collective model (1) and of the individual problem (2) can be written for $j=1, \ldots, m$ as follows:

$$
\tilde{c}_{j}^{i}+R c^{i}=\tilde{\rho}_{j}^{i}+R \rho^{i}
$$

and

$$
\tilde{c}_{j}^{i}+R c^{i}=\tilde{y}_{j}^{i}+R y^{i}
$$

The first period individual income expansion paths with and without risk sharing can therefore be written in the following form:

$$
c^{i *}=c^{i}\left(\tilde{\rho}_{1}^{i}+R \rho^{i}, \ldots, \tilde{\rho}_{m}^{i}+R \rho^{i}\right),
$$

and

$$
\bar{c}^{i}=c^{i}\left(\tilde{y}_{1}^{i}+R y^{i}, \ldots, \tilde{y}_{m}^{i}+R y^{i}\right)
$$

where $c^{i *}$ and $\bar{c}^{i}$ denote optimal individual consumption in the first period with and without risk sharing. Consequently, the main effect of risk sharing is to shift the household members along their income expansion paths.

The next two sections are dedicated to analyzing the properties of the individual Engel curves and their impact on precautionary saving and consumption smoothing. 


\subsection{Efficient Risk Sharing and Precautionary Saving}

To focus on precautionary saving, it is assumed that $R \beta=1$. Consider first a household in which the individual members have identical preferences, discount factors, beliefs and decision power. Under these conditions, the Engel curves are identical across agents and the efficient sharing rule can be written as follows:

$$
\rho^{i}=\frac{Y}{2} \quad \text { and } \quad \tilde{\rho}^{i}=\frac{\tilde{Y}}{2}
$$

where $Y=y^{1}+y^{2}$ and $\tilde{Y}=\tilde{y}^{1}+\tilde{y}^{2}$. The first period individual income expansion paths with and without risk sharing can therefore be written in the following form:

$$
c^{i *}=c\left(\frac{\tilde{Y}_{1}+R Y}{2}, \ldots, \frac{\tilde{Y}_{m}+R Y}{2}\right),
$$

and

$$
\bar{c}^{i}=c\left(\tilde{y}_{1}^{i}+R y^{i}, \ldots, \tilde{y}_{m}^{i}+R y^{i}\right)
$$

Household saving is equal to first period household income minus first period household consumption. Hence, under the assumption of identical agents, efficient risk sharing always reduces saving if and only if the income expansion paths are concave in the $m$ variables.

In an environment with uncertainty the concavity of the Engel curves depends on absolute prudence. To see this note that the income expansion paths with and without risk sharing must satisfy the individual Euler equations, which can be written as follows:

$$
c^{i *}=\left(u^{\prime}\right)^{-1}\left(E\left[u^{\prime}\left(\frac{\tilde{Y}+R Y}{2}-R c^{i *}\right)\right]\right),
$$

and

$$
\bar{c}^{i}=\left(u^{\prime}\right)^{-1}\left(E\left[u^{\prime}\left(\tilde{y}^{i}+R y^{i}-R \bar{c}^{i}\right)\right]\right) .
$$

Using these intertemporal optimality conditions, it is straightforward to show that the Engel curves are concave if and only if the function $g\left(x_{1}, \ldots, x_{m}\right)=\left(u^{\prime}\right)^{-1}\left(E\left[u^{\prime}(\tilde{x})\right]\right)$ is concave in its $m$ arguments. According to Godfrey H. Hardy, John E. Littlewood and George Polya (1952), this condition is satisfied if and only if the inverse of absolute prudence is convex. Therefore, under the assumption of identical agents, efficient risk sharing always reduces saving if and only if the inverse of absolute prudence is convex. The ISHARA class is a subset of all the households satisfying this restriction. 
Consider now a household with heterogeneous agents and concave Engel curves. The difference between consumption with and without risk sharing can be written in the following form:

$$
\begin{gathered}
\sum_{i=1}^{2} c^{i}\left(\tilde{\rho}_{1}^{i}+R \rho^{i}, \ldots, \tilde{\rho}_{m}^{i}+R \rho^{i}\right)-\sum_{i=1}^{2} c^{i}\left(\tilde{y}_{1}^{i}+R y^{i}, \ldots, \tilde{y}_{m}^{i}+R y^{i}\right) \\
=c^{1}\left(\tilde{y}_{1}^{1}+R y^{1}+\tilde{\Delta}_{1}, \ldots, \tilde{y}_{m}^{1}+R y^{1}+\tilde{\Delta}_{m}\right)+c^{2}\left(\tilde{y}_{1}^{2}+R y^{2}-\tilde{\Delta}_{1}, \ldots, \tilde{y}_{m}^{2}+R y^{2}-\tilde{\Delta}_{m}\right) \\
-\sum_{i=1}^{2} c^{i}\left(\tilde{y}_{1}^{i}+R y^{i}, \ldots, \tilde{y}_{m}^{i}+R y^{i}\right) \leq \sum_{j=1}^{m}\left(\frac{\partial c^{1}}{\partial y_{j}}-\frac{\partial c^{2}}{\partial y_{j}}\right) \tilde{\Delta}_{j},
\end{gathered}
$$

where $\tilde{\Delta}_{j}=\tilde{\rho}_{j}^{1}+R \rho^{1}-\left(\tilde{y}_{j}^{1}+R y^{1}\right)=\tilde{y}_{j}^{2}+R y^{2}-\left(\tilde{\rho}_{j}^{2}+R \rho^{2}\right)$ by the feasibility conditions and the inequality follows from the concavity of the Engel curves. Using this result it is straightforward to argue that efficient risk sharing increases saving if the transfers to the agent with the less steep Engel curves are sufficiently large. For instance, consider a household in which the two agents have identical income processes and decision power. In addition, suppose that $\frac{\partial c^{1}}{\partial y_{j}}>\frac{\partial c^{2}}{\partial y_{j}}$ in all states of nature and agent 1 is the least risk averse agent. Then in any adverse state of nature, the least risk averse agent will transfer some of her resources implying that $\tilde{\Delta}_{j}<0$. In any good state of nature, the most risk averse agent will make the transfer, which implies that $\tilde{\Delta}_{j}>0$. Consequently, if the adverse income realizations dominate the good income realizations, efficient risk sharing increases saving. This indicates that, with heterogeneous agents, the conditions required for risk sharing to always reduce saving are stronger than linearity or concavity.

Consider a household in which the Engel curves are linear and have identical slopes with respect to every income process. The previous argument suggests that under these conditions risk sharing can never increase saving. However, these restrictions are too strong since they also eliminate the income pooling effect. Consider now an ISHARA household. In this case, the individual Engel curves are linear with identical slopes if household members can allocate risk efficiently. Consequently, the insurance component of risk sharing has no effect on household aggregate behavior. If risk cannot be allocated efficiently, however, the income expansion paths are concave, which implies that income pooling has the intuitive effect of reducing saving. Specifically, for an ISHARA household, individual Euler equations with and without risk sharing can be written as follows:

$$
c^{i *}=\left(E\left[\left(a_{i}+\tilde{\rho}^{i}+R \rho^{i}-R c^{i *}\right)^{-\gamma}\right]\right)^{-\frac{1}{\gamma}}-a_{i}
$$


and

$$
\bar{c}^{i}=\left(E\left[\left(a_{i}+\tilde{y}^{i}+R y^{i}-R \bar{c}^{i}\right)^{-\gamma}\right]\right)^{-\frac{1}{\gamma}}-a_{i} .
$$

Consider the function $h\left(x_{1}, \ldots, x_{m}\right)=\left(E\left[\tilde{x}^{-\gamma}\right]\right)^{-\frac{1}{\gamma}}$. The Engel curves are concave, respectively linear, if the function $h$ is concave, respectively linear, in its $m$ arguments. Hardy, Littlewood and Polya (1952) show that $h$ is concave in its $m$ arguments for any non-negative random variables $\tilde{x}^{1}$ and $\tilde{x}^{2}$ and $\gamma>0$, unless $x_{j}^{1}=A x_{j}^{2}$ in every state of nature for some constant $A$, in which case the function is linear. The efficient allocation of risk requires the ratio of marginal utilities to be constant across states of nature, which implies that

$$
a_{1}+\tilde{\rho}^{1}+R \rho^{1}-R c^{1 *}=B\left(a_{2}+\tilde{\rho}^{2}+R \rho^{2}-R c^{2 *}\right)
$$

in each state of nature for some constant $B$. Consequently, under efficiency the function $h$ is linear and the individual Engel curves are identical and linear in $a_{i}+\tilde{\rho}^{i}+R \rho^{i}$. If risk is not allocated efficiently, the proportionality condition is generally not satisfied. As a result, the function $h$ is concave and the individual Engel curves are identical and concave in $a_{i}+\tilde{y}^{i}+R y^{i}$. Therefore, the difference between first period consumption with and without risk sharing can be written in the following form:

$$
\begin{gathered}
\sum_{i=1}^{2} c\left(a_{i}+\tilde{\rho}_{1}^{i}+R \rho^{i}, \ldots, a_{i}+\tilde{\rho}_{m}^{i}+R \rho^{i}\right)-\sum_{i=1}^{2} c\left(a_{i}+\tilde{y}_{1}^{i}+R y^{i}, \ldots, a_{i}+\tilde{y}_{m}^{i}+R y^{i}\right) \\
=2 c\left(\sum_{i=1}^{2} \frac{a_{i}+\tilde{y}_{1}^{i}+R y^{i}}{2}, \ldots, \sum_{i=1}^{2} \frac{a_{i}+\tilde{y}_{m}^{i}+R y^{i}}{2}\right)-2 \sum_{i=1}^{2} \frac{c\left(a_{i}+\tilde{y}_{1}^{i}+R y^{i}, \ldots, a_{i}+\tilde{y}_{m}^{i}+R y^{i}\right)}{2} \geq 0,
\end{gathered}
$$

where the equality, which describes the insurance effect, follows from the linearity and the feasibility conditions, and the inequality, which describes income pooling, follows from the concavity. Therefore, it can be concluded that an ISHARA household is a sufficient condition for risk sharing to always reduce saving. Moreover, since the ISHARA class is the only group of households for which the insurance component of risk sharing has no effect on household aggregate behavior, the restriction is also necessary.

\subsection{Efficient Risk Sharing and Consumption Smoothing}

To evaluate the effect of the optimal allocation of resources on consumption smoothing, consider a household with identical agents living in a risk-free environment, in which $R \beta$ differs from 1 . As 
for precautionary saving, if agents are identical the efficient allocation of resources always reduces saving if and only if the Engel curves are concave. Gollier (2001a, b) shows that in this environment the concavity depends on absolute risk tolerance, which is defined as the inverse of absolute risk aversion. Specifically, if $R \beta>1$ (resp. $R \beta<1$ ) the income expansion paths are concave if and only if absolute risk tolerance is convex (resp. concave). ISHARA households have linear absolute risk tolerances which implies that the restriction is always satisfied.

If the assumption of identical agents is relaxed, however, concavity of the Engel curves is no longer sufficient. For example, suppose that the household members have identical preferences but different decision power and that the Engel curves are concave. It is then always possible to choose income processes and decision power such that

$$
\tilde{\rho}^{1}+R \rho^{1}>\tilde{y}^{1}+R y^{1} \geq \tilde{y}^{2}+R y^{2}>\tilde{\rho}^{2}+R \rho^{2}
$$

which implies by concavity of the Engel curves that the insurance component of risk sharing increases saving. ${ }^{18}$ This result suggests that, allowing for heterogeneity in Pareto weights, risk sharing always decreases the consumption smoothing component of saving if and only if the income expansion paths are linear. Gollier (2001b) shows that with no uncertainty the income expansion paths are linear if and only if preferences belongs to the HARA class.

Consider now a household in which the individual members have HARA preferences with heterogenous curvature parameters. It is straightforward to show that in this case the individual Engel curves are linear with different slopes across agents. By exploiting the variation in the individual slopes it is always possible to find income processes and Pareto weight for which efficient risk sharing increases saving. All this indicates that risk sharing always decreases the consumption smoothing component of saving if and only if the income expansion paths are linear with identical slopes. Under the assumptions of this section, only ISHARA households have linear Engel curves with identical slopes.

\footnotetext{
${ }^{18}$ In this case, the welfare of the member making the transfer may be higher relative to autarky because of additive altruism or a separable public good.
} 


\section{Household Risk Preferences and Saving}

The previous section suggests a potential explanation for the finding that saving of couples can be a U-shaped function of individual prudence and risk aversion. To develop a more direct understanding of this result, it is useful to analyze the relationship between household and individual risk preferences.

Under full efficiency, each household can be characterized using the corresponding representative agent, which can be determined by solving the following problem:

$$
\begin{gathered}
v_{\mu}(W)=\max _{c^{1}, c^{2}} \mu_{1} u^{1}\left(c^{1}\right)+\mu_{2} u^{2}\left(c^{2}\right) \\
\text { s.t. } c^{1}+c^{2}=W,
\end{gathered}
$$

where the subscript $\mu$ indicates that $v_{\mu}$ is defined for a given set of Pareto weights. A well-known result in the literature on group decisions is that the solution of the intertemporal collective model is equivalent to the solution of the following problem:

$$
\begin{gathered}
\max _{C, \tilde{C}, s} v_{\mu}(C)+\beta E\left[v_{\mu}(\tilde{C})\right] \\
\text { s.t. } C+s=Y \\
\tilde{C}=\tilde{Y}+R s
\end{gathered}
$$

where $C$ and $\tilde{C}$ are household total consumption in the first and second period. It is therefore natural to define household preferences as the preferences of the representative agent $v_{\mu}$. Household absolute risk aversion and prudence can then be computed as $-v_{\mu}^{\prime \prime}(W) / v_{\mu}^{\prime}(W)$ and $-v_{\mu}^{\prime \prime \prime}(W) / v_{\mu}^{\prime \prime}(W)$. Accordingly, household relative risk aversion and prudence can be defined as $-W v_{\mu}^{\prime \prime}(W) / v_{\mu}^{\prime}(W)$ and $-W v_{\mu}^{\prime \prime \prime}(W) / v_{\mu}^{\prime \prime}(W)$. All this clarifies that saving decisions depend on household risk preferences and only indirectly on individual risk preferences. Only if there is a monotone relationship between them, saving can be characterized using individual risk aversion and prudence.

Consider two households in which the two members have the following HARA preferences:

$$
u^{1}(c)=\frac{\left(a_{1}+c\right)^{1-\gamma_{1}}}{1-\gamma_{1}} \text { and } u^{2}(c)=\frac{\left(a_{2}+c\right)^{1-\gamma_{2}}}{\delta\left(1-\gamma_{2}\right)}
$$


where the parameter $\delta$ is required to allow for an arbitrary threshold $\bar{C} \cdot{ }^{19}$ Suppose that the two households are identical except that the husband's curvature parameter in household 1 is larger than the curvature parameter of the husband in household 2. As a consequence, the husband in household 1 is more risk averse and prudent than the husband in household 2 for any level of consumption in absolute and relative terms. The following result states that household 1 can be less risk averse and less prudent in absolute as well as in relative terms.

Theorem 2 Assume HARA preferences, $\gamma_{1} \neq \gamma_{2}$ and without loss of generality $\gamma_{1}>\gamma_{2}$. Let $r_{\mu}$ and $p_{\mu}$ be household absolute risk aversion and prudence. Then, there exists a $\hat{W}>0$ such that,

$$
\frac{\partial r_{\mu}\left(W, \bar{C}, \gamma_{1}, \gamma_{2}\right)}{\partial \gamma_{2}}<0 \text { for any } W \in[0, \hat{W})
$$

Moreover, if $\gamma_{2} \geq 1$,

$$
\frac{\partial p_{\mu}\left(W, \bar{C}, \gamma_{1}, \gamma_{2}\right)}{\partial \gamma_{2}}<0 \text { for any } W \in[0, \hat{W})
$$

Proof. In the appendix.

To outline the main intuition behind theorem 2, it is convenient to use the concept of absolute risk tolerance and a result by Wilson (1968) which states that household absolute risk tolerance, $T(W)$, is the sum of individual absolute risk tolerances, $t_{i}(W)$. Consider a household with CRRA preferences and identical decision power, in which agent 2 is the least risk averse agent. Under these conditions, member $i$ 's absolute risk tolerance is linear and the slope is decreasing in the curvature parameter $\gamma_{i}$. Suppose that $\gamma_{2}$ increases by $\epsilon$. This has two different effects. First, for a given allocation of resources, the addition of $\epsilon$ reduces member 2's absolute risk tolerance and consequently the household absolute risk tolerance. Second, resources are optimally reallocated to take into account the variation in risk preferences. This second effect varies the absolute risk tolerance of the two agents in opposite directions. Consequently, the reallocation effect can increase or decrease the household absolute risk tolerance depending on the magnitude of the individual adjustments. To quantify the two effects, let $\Delta(\epsilon)$ be the additional amount of resources transferred

\footnotetext{
${ }^{19}$ Since the utility functions are von Neumann-Morgenstern utility functions, $\delta$ can be normalized to be equal to 1 . However, it is straightforward to show that $\delta=\left(\left(\bar{C}+a_{1}+a_{2}\right) / 2\right)^{\gamma_{1}-\gamma_{2}} \mu_{2} / \mu_{1}$, which implies that the normalization fixes $\bar{C}$ to a specific value. For example, under CRRA preferences and identical Pareto weights, this normalization implies $\bar{C}=2$. From an empirical and numerical viewpoint, it is important to allow for an arbitrary $\bar{C}$. Consequently, in this paper $\delta$ is not normalized.
} 
to member 2 because of higher risk aversion and denote with $\Delta^{\prime}(0)$ its derivative at $\epsilon=0$. The change in household absolute risk tolerance for $\epsilon$ small can then be written in the following form:

$$
\Delta T=-\frac{t_{2}}{\gamma_{2}} \epsilon-\frac{\Delta^{\prime}(0) \epsilon}{\gamma_{1}}+\frac{\Delta^{\prime}(0) \epsilon}{\gamma_{2}} .
$$

In equation (4), the change in household risk tolerance is composed of three parts. The first term captures the direct effect, which has always the intuitive negative sign. The second and third terms describe the change in risk tolerance of members 1 and 2 induced by the reallocation of resources.

It is important to outline some properties of the reallocation effect. First, if the household experiences an adverse income realization, the amount of resources reallocated from member 1 to member 2 is strictly positive, that is $\Delta^{\prime}(0) \epsilon>0$. This implies that the reallocation effect always increases household absolute risk tolerance for low income realizations, since the slope of member 2's absolute risk tolerance is larger. Second, the first order conditions of (3) imply that $\Delta^{\prime}(0) \epsilon=\frac{t_{1} t_{2}}{t_{1}+t_{2}} \epsilon \log \frac{c^{2}}{\bar{C} / 2}$. Consequently, $\Delta T>0$ if and only if

$$
-\frac{1}{\gamma_{2}}-\frac{\gamma_{1}-\gamma_{2}}{\gamma_{1}} \frac{t_{1}}{t_{1}+t_{2}} \log \frac{c^{2}}{\bar{C} / 2}>0
$$

Since $c^{2}$ is an increasing function of household income, this inequality implies that for fixed $\gamma_{1}$ and $\gamma_{2}$ the reallocation effect dominates the direct effect if household resources are sufficiently low. Moreover, for fixed household resources, it indicates that the reallocation effect is increasing in the difference between $\gamma_{1}$ and $\gamma_{2}{ }^{20}$

Figure 2 depicts household relative risk aversion and prudence for the group of households considered in the numerical example of section II as a function of the husband's relative risk aversion and prudence. ${ }^{21}$ Figure 2 illustrates that, contrary to the standard intuition, household risk aversion and prudence can be a decreasing function of the husband's risk aversion and prudence if the difference between the wife's and the husband's curvature parameter is sufficiently large. It can be shown that this result applies to all households in which individual members have HARA preferences. This

\footnotetext{
${ }^{20}$ The inverse of household prudence is not equal to the sum of the inverse of individual prudences. However, it is possible to show that for the households considered in this section the sign of $\partial p_{\mu} / \partial \gamma_{2}$ is approximately equal to the sign of $\partial r_{\mu} / \partial \gamma_{2}$. Consequently, this argument applies indirectly also to prudence. I am grateful to Christian Gollier for pointing this out. Hara and Kuzmics (2002) consider a problem related to the one discussed in this section. Specifically, they analyze how the representative agent risk aversion varies by changing the total amount of resources.

${ }^{21}$ The shape of household absolute risk aversion and prudence mirrors the shape of household relative risk aversion and prudence. A description of the derivation of Figure 2 is contained in Mazzocco (2003a).
} 


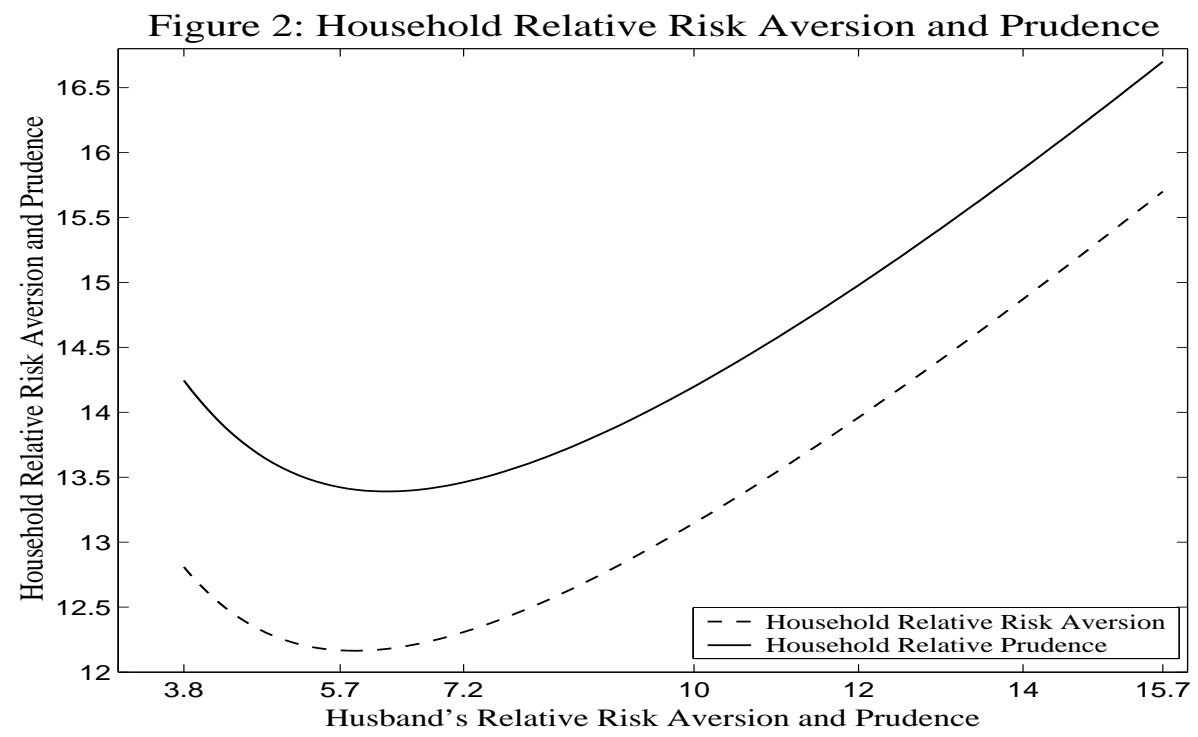

finding explains the U-shaped saving function of Figure 1. Specifically, saving is decreasing in individual risk aversion and prudence as long as household risk preferences are decreasing in individual risk preferences.

There is a growing literature which makes use of survey measures of individual risk preferences to understand variations across households in saving and portfolio decisions. For example, Barsky et al. (1997) and Kerwin Kofi Charles and Erik Hurst (2003) analyze household portfolio choices by regressing portfolio shares on a set of control variables and individual risk preferences. The results of this section indicate that household decisions depend on the risk preferences of the representative agent corresponding to the household and only indirectly on individual risk preferences. Consequently, it is not sufficient to use individual risk aversion and prudence to analyze saving and portfolio decisions. Additional information on the intra-household allocation of resources is required.

The results of the present paper may also provide a rationale for the mixed evidence in the empirical literature on precautionary saving. Note that the findings of this paper indicate that the correct measure of risk to determine the precautionary motive is the uncertainty intrinsic in the sharing rule, $\left\{\rho^{i}, \tilde{\rho}^{i}\right\}_{i=1,2}$, because it summarizes the income pooling as well as the insurance component of risk sharing. The majority of the empirical papers on saving, however, use the uncertainty that characterizes household income to determine the significance of the precautionary motive. Since household 
income captures only the income pooling effect, the findings of these papers overestimate or underestimate the precautionary motive depending on the strength and the direction of the insurance effect in the sample used in the estimation. For instance, this may clarify why Carroll and Andrew A. Samwick (1998) find that the precautionary motive explains a sizable part of wealth holdings using a sample representative of the US population, whereas Luigi Guiso, Tullio Jappelli and Daniele Terlizzese (1992) find little or no evidence in favor of the precautionary motive employing a sample of Italian households.

\section{Conclusions}

In this paper, saving is characterized as the outcome of the joint decision of household members to capture the effect of risk sharing on saving patterns. I find that the optimal allocation of risk across household members has two important effects on saving. First, it can increase the amount saved by the household. Second, it generates the counterintuitive result that an increase in the willingness to save of one agent can reduce the willingness to save of the household and therefore total saving. These findings may be used to interpret the saving patterns of couples observed in the HRS.

The present research can be extended in at least two directions. First, Browning et al. (1994) and Chiappori et al. (2002) estimate the intra-household allocation of resources in a static framework and find that it has a significant effect on household consumption. In Mazzocco (2003c) individual Euler equations are identified and estimated using data on total household consumption, individual labor supply and wages. The results of the present paper suggest that to understand saving behavior, as well as for addressing important policy questions, it will be crucial to extend these identification and estimation results to a stochastic framework dealing explicitly with saving decisions. Second, the main weakness of the model proposed in the present paper is that household formation is not considered. Since the choice of the spouse is endogenous, more work is needed to establish whether saving patterns are affected by matching based on risk preferences. 


\section{References}

[1] Attanasio, Orazio P. and Mazzocco, Maurizio. "Intrahousehold Allocation with Limited Commitment: An Empirical Characterization.” Working Paper, University of Wisconsin-Madison, 2003.

[2] Barsky, Robert B.; Juster Thomas F.; Kimball Miles S. and Shapiro, Matthew D. "Preference Parameters and Behavioral Heterogeneity: An Experimental Approach in the Health and Retirement Study." Quarterly Journal of Economics, May 1997, 112(2), pp. 537-579.

[3] Becker, Gary S. A Treatise of the Family. Cambridge, Massachusetts: Harvard University Press, 1991.

[4] Browning, Martin. “The Saving Behavior of a Two-person Household." Scandinavian Journal of Economics, June 2000, 102(2), pp. 235-251.

[5] Browning, Martin; Bourguignon, Francois; Chiappori, Pierre-André and Lechene, Valerie. "Income and Outcomes: A Structural Model of Intrahousehold Allocation." Journal of Political Economy, October 1994, 102(5), pp. 1067-1096.

[6] Browning, Martin and Lusardi, Annamaria. "Household Saving: Micro Theories and Micro Facts." Journal of Economic Literature, December 1996, 34(4), pp. 1797-1855.

[7] Carroll, Christopher D. and Kimball, Miles S. "On the Concavity of the Consumption Function.” Econometrica, July 1996, 64(4), pp. 981-992.

[8] Carroll, Christopher D. and Samwick, Andrew A. "How Important is Precautionary Saving?" The Review of Economics and Statistics, August 1998, 80(3), pp. 410-419.

[9] Charles, Kerwin Kofi and Hurst, Erik. "The Correlation of Wealth across Generations." Journal of Political Economy, December 2003, 111(6), pp. 1155-1182.

[10] Chiappori, Pierre-André. "Rational Household Labor Supply.” Econometrica, January 1988, 56(1), pp. 63-90.

[11] Chiappori, Pierre-André. “Collective Labor Supply and Welfare.” Journal of Political Economy, June 1992, 100(3), pp. 437-467.

[12] Chiappori, Pierre-André; Fortin, Bernard and Lacroix, Guy. "Marriage Market, Divorce Legislation and Household Labor Supply." Journal of Political Economy, February 2002, 110(1), pp. 37-72.

[13] Gollier, Christian. "Wealth Inequality and Asset Pricing." Review of Economic Studies, January 2001a, 68(1), pp. 181-203.

[14] Gollier, Christian. The Economics of Risk and Time. Cambridge, Massachusetts: M.I.T. Press, $2001 b$. 
[15] Guiso, Luigi; Jappelli, Tullio and Terlizzese, Daniele. "Earnings Uncertainty and Precautionary Saving.” Journal of Monetary Economics, (Nov. 1992), 30(2), pp. 307-337.

[16] Hara, Chiaki and Christoph A. Kuzmics: "Representative Consumer's Risk Aversion and Efficient Risk-Sharing Rules," Manuscript, University of Cambridge (Oct. 2002).

[17] Hardy, Godfrey H.; Littlewood, John E. and Polya, George. Inequalities. Cambridge, United Kingdom: Cambridge University Press, 1952.

[18] Lundberg, Shelly; Startz, Richard and Stillman, Steven. "The Retirement-Consumption Puzzle: A Marital Bargaining Approach.” Journal of Public Economics, forthcoming.

[19] Juster, Thomas F. and Smith, James P. "Improving the Quality of Economic Data: Lessons from HRS and AHEAD." Journal of the American Statistical Association, December 1997, 92(440), pp. 1268-1278.

[20] Juster, Thomas F. and Suzman, Richard. "An Overview of the Health and Retirement Study." Journal of Human Resources, 1995, Special Issue on the Health and Retirement Study: Data Quality and Early Results, 30, pp. S7-S56.

[21] Kimball, Miles S. "Precautionary Saving in the Small and in the Large." Econometrica, January 1990, 58(1), pp. 53-73.

[22] Mazzocco, Maurizio. "Saving, Risk Sharing and Preferences for Risk." Working Paper, University of Wisconsin, 2003a.

[23] Mazzocco, Maurizio. "Household Intertemporal Behavior: a Collective Characterization and Empirical Tests." Manuscript, University of Wisconsin, 2003b.

[24] Mazzocco, Maurizio. "Individual Euler Equations Rather Than Household Euler Equations." Working Paper, University of Wisconsin, (2003c).

[25] Pratt, John W. "Risk Aversion in the Small and in the Large." Econometrica, January-April 1964, 32(1/2), pp. 122-136.

[26] Pratt, John W. and Zeckhauser, Richard J. "The Impact of Risk Sharing on Efficient Decision." Journal of Risk and Uncertainty, 1989, 2(3), pp. 219-34.

[27] Smith, James P. "Racial and Ethnic Differences in Wealth in the Health and Retirement Study." The Journal of Human Resources, 1995, Special Issue on the Health and Retirement Study: Data Quality and Early Results, 30, pp. S158-S183.

[28] Wilson, Robert. “The Theory of Syndicates." Econometrica, January 1968, 36(1), pp. 119-132. 


\section{A Proof of theorem 1}

The following two lemmas are required in the proof of theorem 1. The first lemma is theorem 198 in Hardy, Littlewood and Polya (1997). The second lemma is theorem 1 in Mazzocco (2002a).

Lemma 3 Let $x_{1}$ and $x_{2}$ be nonnegative random variables defined on $(\Omega, \mathfrak{F})$ and finite almost everywhere. Set $x=x_{1}+x_{2}$. If $\gamma \in \mathbb{R}$ and $\gamma<0$, then the function $\left(\int x^{\gamma} d P\right)^{\frac{1}{\gamma}}$ is concave in $x$ or equivalently (given homogeneity of degree 1 ),

$$
\left(\int x^{\gamma} d P\right)^{\frac{1}{\gamma}} \geq\left(\int x_{1}^{\gamma} d P\right)^{\frac{1}{\gamma}}+\left(\int x_{2}^{\gamma} d P\right)^{\frac{1}{\gamma}}
$$

If $P\left[\left\{\omega \in \Omega: A x_{1}(\omega)=B x_{2}(\omega)\right\}\right]<1$ and $P\left[\left\{\omega \in \Omega: x_{1}(\omega)=x_{2}(\omega)=0\right\}\right]=0$ for any two constants $A$ and $B$, then

$$
\left(\int x^{\gamma} d P\right)^{\frac{1}{\gamma}}>\left(\int x_{1}^{\gamma} d P\right)^{\frac{1}{\gamma}}+\left(\int x_{2}^{\gamma} d P\right)^{\frac{1}{\gamma}}
$$

Proof. Hardy, Littlewood and Polya (1997).

Let $\tilde{\tilde{\rho}}^{i}=\tilde{\rho}^{i}+R \rho^{i}$ and $\tilde{\tilde{Y}}=\tilde{Y}+R Y$. Household exact aggregation is defined as follows:

$$
C^{*}\left(\tilde{\tilde{\rho}}^{1}, \tilde{\tilde{\rho}}^{2}\right)=C^{*}\left(\tilde{\tilde{Y}}^{i}\right) \text { for any } \tilde{Y}, Y, \mu,
$$

i.e. only total income affects total consumption and therefore savings.

Lemma 4 Household exact aggregation is satisfied if and only if the household belongs to the ISHARA class.

Proof. Mazzocco (2002a)

It is now possible to prove Theorem 1.

Proof. (Sufficient condition) Assume $n=2$. The proof for an arbitrary $n$ can be obtained iterating $n-1$ times the same argument. Let $\left\{\rho^{i *}, \tilde{\rho}^{i *}, c^{i *}, \tilde{c}^{i *}, s^{i *}\right\}_{i=1,2}$ be the solution of the two stage formulation of the household problem. Let $\left\{\bar{c}^{i}, \tilde{\bar{c}}^{i}, \bar{s}^{i}\right\}_{i=1,2}$ be the solution of standard individual problem. Let $\bar{C}=\bar{c}^{1}+\bar{c}^{2}$ and $C^{*}=c^{1 *}+c^{2 *}$. By assumption household members have identical discount factors, identical beliefs and HARA preferences with identical curvature parameters. Hence,

$$
\left(u^{i \prime}\right)^{-1}\left(\beta R E\left[u^{i \prime}\left(\tilde{c}^{i}\right)\right]\right)=\left(\left(\beta R E\left[\left(a_{i}+\tilde{c}^{i}\right)^{-\gamma}\right]\right)^{-\frac{1}{\gamma}}-a_{i}\right) .
$$

Since

$$
\left(u^{i \prime}\right)^{-1}\left(\beta R E\left[u^{i \prime}\left(\tilde{c}^{i}\right)\right]\right)=(\beta R)^{-\frac{1}{\gamma}}\left(u^{i \prime}\right)^{-1}\left(E\left[u^{i \prime}\left(\tilde{c}^{i}\right)\right]\right)
$$

for each individual member, it is possible to assume without loss of generality that $\beta R=1$.

Assume $C^{*}<\bar{C}$. The first order conditions of standard individual problem imply,

$$
\bar{c}^{i}=\left(u^{i \prime}\right)^{-1}\left(E\left[u^{i \prime}\left(\tilde{y}^{i}+R\left(y^{i}-\bar{c}^{i}\right)\right)\right]\right) .
$$


The first order conditions of the second stage of the household problem imply,

$$
c^{i *}=\left(u^{i \prime}\right)^{-1}\left(E\left[u^{i \prime}\left(\tilde{\rho}^{i *}+R\left(\rho^{i *}-c^{i *}\right)\right)\right]\right) .
$$

By equations (5) and (7) we have,

$$
\begin{aligned}
C^{*} & =\left(\left(E\left[\left(a_{1}+\tilde{\rho}^{1 *}+R\left(\rho^{1 *}-c^{1 *}\right)\right)^{-\gamma}\right]\right)^{-\frac{1}{\gamma}}-a_{1}\right)+ \\
& +\left(\left(E\left[\left(a_{2}+\tilde{\rho}^{2 *}+R\left(\rho^{2 *}-c^{2 *}\right)\right)^{-\gamma}\right]\right)^{-\frac{1}{\gamma}}-a_{2}\right) .
\end{aligned}
$$

Since $\left\{\rho^{i *}, \tilde{\rho}^{i *}, c^{i *}, \tilde{c}^{i *}, s^{i *}\right\}_{i=1,2}$ is the solution of the two stage household problem, it must satisfy the first order conditions of the first stage of the collective model,

$$
\left(a_{1}+\tilde{\rho}^{1 *}+R\left(\rho^{1 *}-c^{1 *}\right)\right)^{-\gamma}=\mu\left(a_{2}+\tilde{\rho}^{2 *}+R\left(\rho^{2 *}-c^{2 *}\right)\right)^{-\gamma} \text { for any } \omega \in \Omega,
$$

where $\mu=\mu_{2} / \mu_{1}$. Let $\mu^{\prime}=\mu^{-\frac{1}{\gamma}}$. Substituting in (8) and using the feasibility conditions $Y=$ $\rho^{1 *}+\rho^{2 *}$ and $\tilde{Y}(\omega)=\tilde{\rho}^{1 *}(\omega)+\tilde{\rho}^{2 *}(\omega)$ for any $\omega \in \Omega$,

$$
\begin{aligned}
C^{*} & =\left(1+\mu^{\prime}\right)\left(E\left[\left(a_{2}+\tilde{\rho}^{2 *}+R\left(\rho^{2 *}-c^{2 *}\right)\right)^{-\gamma}\right]\right)^{-\frac{1}{\gamma}}-a_{1}-a_{2} \\
& =\left(1+\mu^{\prime}\right)\left(E\left[\left(\frac{a_{2}+\tilde{\rho}^{2 *}+R\left(\rho^{2 *}-c^{2 *}\right)+\mu^{\prime}\left(a_{2}+\tilde{\rho}^{2 *}+R\left(\rho^{2 *}-c^{2 *}\right)\right)}{\left(1+\mu^{\prime}\right)}\right)^{-\gamma}\right]\right)^{-\frac{1}{\gamma}} \\
& -a_{1}-a_{2} \\
& =\left(E\left[\left(a_{1}+a_{2}+\tilde{Y}+R\left(Y-c^{1 *}-c^{2 *}\right)\right)^{-\gamma}\right]\right)^{-\frac{1}{\gamma}}-a_{1}-a_{2} .
\end{aligned}
$$

Note that $\left(E\left[\left(a_{1}+a_{2}+\tilde{Y}+R(Y-C)\right)^{-\gamma}\right]\right)^{-\frac{1}{\gamma}}$ is decreasing in $C$. Moreover $a_{i}+\tilde{y}^{i}+$ $R\left(y^{i}-\bar{c}^{i}\right) \geq 0$ under the assumption of permissible income. Hence, by $C^{*}<\bar{C}$, lemma $3, Y=$ $y^{1}+y^{2}, \tilde{Y}(\omega)=\tilde{y}^{1}(\omega)+\tilde{y}^{2}(\omega)$ and $(6)$,

$$
\begin{aligned}
C^{*} & =\left(E\left[\left(a_{1}+a_{2}+\tilde{Y}+R\left(Y-C^{*}\right)\right)^{-\gamma}\right]\right)^{-\frac{1}{\gamma}}-a_{1}-a_{2} \\
& \geq\left(E\left[\left(a_{1}+a_{2}+\tilde{Y}+R(Y-\bar{C})\right)^{-\gamma}\right]\right)^{-\frac{1}{\gamma}}-a_{1}-a_{2} \\
& \geq\left(E\left[\left(a_{1}+\tilde{y}^{1}+R\left(y^{1}-\bar{c}^{1}\right)\right)^{-\gamma}\right]\right)^{-\frac{1}{\gamma}}+\left(E\left[\left(a_{2}+\tilde{y}^{2}+R\left(y^{2}-\bar{c}^{2}\right)\right)^{-\gamma}\right]\right)^{-\frac{1}{\gamma}}-a_{1}-a_{2} \\
& =\left(u^{1 \prime}\right)^{-1}\left(E\left[u^{1 \prime}\left(\tilde{y}^{1}+R\left(y^{1}-\bar{c}^{1}\right)\right)\right]\right)+\left(u^{2 \prime}\right)^{-1}\left(E\left[u^{2 \prime}\left(\tilde{y}^{2}+R\left(y^{2}-\bar{c}^{2}\right)\right)\right]\right) \\
& =\bar{c}^{1}+\bar{c}^{2}=\bar{C}
\end{aligned}
$$


which contradict the initial assumption $C^{*}<\bar{C}$. Hence, $C^{*} \geq \bar{C}$. Finally,

$$
s=Y-\left(c^{1}+c^{2}\right)
$$

for any level of consumption, which implies $s^{*} \leq \bar{s}$.

(Necessary condition) I will initially show by contradiction that if risk sharing always reduces savings, then household consumption must satisfy household exact aggregation

Assume $s^{*} \leq \bar{s}$ always. Assume exact aggregation is not satisfied. This implies that there exist total incomes, $\overline{\tilde{Y}}$ and $Y$, and ratios of Pareto weights, $m u^{\prime}$ and $\mu^{\prime \prime}$, such that the corresponding allocation of resources, $\left\{\tilde{\tilde{\rho}}^{1 \prime}, \tilde{\tilde{\rho}}^{2 \prime}\right\}$ and $\left\{\tilde{\tilde{\rho}}^{1 \prime \prime}, \tilde{\tilde{\rho}}^{2 \prime \prime}\right\}$, satisfy the following conditions:

$$
\tilde{\tilde{\rho}}^{1 \prime}+\tilde{\tilde{\rho}}^{2 \prime}=\tilde{\tilde{\rho}}^{1 \prime \prime}+\tilde{\tilde{\rho}}^{2 \prime \prime}=\tilde{\tilde{Y}}
$$

and

$$
c^{1 *}\left(\tilde{\tilde{\rho}}^{1 \prime}\right)+c^{2 *}\left(\tilde{\tilde{\rho}}^{2 \prime}\right) \neq c^{1 *}\left(\tilde{\tilde{\rho}}^{1 \prime \prime}\right)+c^{2 *}\left(\tilde{W}^{2 \prime \prime}\right) .
$$

Assume without loss of generality that,

$$
c^{1 *}\left(\tilde{\tilde{\rho}}^{1 \prime}\right)+c^{2 *}\left(\tilde{\tilde{\rho}}^{2 \prime}\right)>c^{1 *}\left(\tilde{\tilde{\rho}}^{1 \prime \prime}\right)+c^{2 *}\left(\tilde{\tilde{\rho}}^{2 \prime \prime}\right) .
$$

Choose $\tilde{y}^{1}, \tilde{y}^{2}, y^{1}$ and $y^{2}$ such that,

$$
\begin{aligned}
& \tilde{y}^{1}+R y^{1}=\tilde{\tilde{\rho}}^{1 \prime} \\
& \tilde{y}^{2}+R y^{2}=\tilde{\tilde{\rho}}^{2 \prime} .
\end{aligned}
$$

Moreover, set $\mu=\mu^{\prime \prime}$. By construction this implies,

$$
\begin{aligned}
& \tilde{\rho}^{1}+R \rho^{1}=\tilde{\tilde{\rho}}^{1 \prime \prime} \\
& \tilde{\rho}^{2}+R \rho^{2}=\tilde{\tilde{\rho}}^{2 \prime \prime}
\end{aligned}
$$

By (9), (10) and (11),

$$
\bar{C}=\bar{c}^{1}+\bar{c}^{2}>c^{1 *}+c^{* 2}=C^{*},
$$

which contradicts the initial assumption. Hence, if risk sharing decreases always savings, exact aggregation must be satisfied. By lemma 4, necessary condition for exact aggregation is that all members have identical discount factors, identical beliefs and HARA preferences with identical shape parameters. This concludes the proof.

\section{B Proof of Theorem 2}

The following lemma is needed to prove theorem 2. It characterizes the measures of household absolute risk aversion and absolute prudence. 
Lemma 5 Let $c^{1 *}$ and $c^{2 *}$ be the solution of the representative agent problem and $r_{\mu}\left(W, \bar{C}, \gamma_{1}, \gamma_{2}\right)$ and $p_{\mu}\left(W, \bar{C}, \gamma_{1}, \gamma_{2}\right)$ be household absolute risk aversion and prudence. Under the assumptions of section 5, household absolute risk aversion prudence can be written in the form,

$$
\begin{aligned}
r_{\mu}\left(W, \bar{C}, \gamma_{1}, \gamma_{2}\right) & =\frac{\gamma_{1} \gamma_{2}}{\gamma_{1}\left(a_{2}+c^{2 *}\right)+\gamma_{2}\left(a_{1}+c^{1 *}\right)} \\
p_{\mu}\left(W, \bar{C}, \gamma_{1}, \gamma_{2}\right) & =\frac{\gamma_{1}+1}{\gamma_{1}} r_{\mu}+\frac{\left(\gamma_{1}-\gamma_{2}\right)\left(a_{2}+c^{2 *}\right)}{\gamma_{1}\left(\gamma_{2}\right)^{2}} r_{\mu}^{2} .
\end{aligned}
$$

Proof. Under the assumption of HARA preferences, the representative agent problem can be written as follows:

$$
\begin{gathered}
v_{\mu}(W)=\max _{c^{1}, c^{2}} \frac{\left(a_{1}+c^{1}\right)^{1-\gamma_{1}}}{1-\gamma_{1}}+\frac{\mu}{\delta} \frac{\left(a_{2}+c^{2}\right)^{1-\gamma_{2}}}{1-\gamma_{2}} \\
\text { s.t. } c^{1}+c^{2}=W .
\end{gathered}
$$

where $\mu=\mu_{2} / \mu_{1}$. Define $\hat{c}^{i}=a_{i}+c^{i}$. Then the represented agent problem can be reformulated as follows:

$$
\begin{gathered}
v_{\mu}(W)=\max _{\hat{c}^{1}, \hat{c}^{2}} \frac{\left(\hat{c}^{1}\right)^{1-\gamma_{1}}}{1-\gamma_{1}}+\frac{\mu}{\delta} \frac{\left(\hat{c}^{2}\right)^{1-\gamma_{2}}}{1-\gamma_{2}} \\
\text { s.t. } \hat{c}^{1}+\hat{c}^{2}=W+a_{1}+a_{2} .
\end{gathered}
$$

The first order conditions imply,

$$
\left(\hat{c}^{1}\right)^{-\gamma_{1}}=\frac{\mu}{\delta}\left(\hat{c}^{2}\right)^{-\gamma_{2}} \text { for any } W
$$

Let $\bar{C}$ be the level of resources, $W$, at which the two spouses split evenly household resources, i.e. $\hat{c}^{1}=\hat{c}^{2}=\frac{\bar{C}+a_{1}+a_{2}}{2}$. The first order condition (12) must hold also for $W=\bar{C}$. Hence,

$$
\left(\frac{\bar{C}+a_{1}+a_{2}}{2}\right)^{-\gamma_{1}}=\frac{\mu}{\delta}\left(\frac{\bar{C}+a_{1}+a_{2}}{2}\right)^{-\gamma_{2}}
$$

which implies,

$$
\frac{\mu}{\delta}=\left(\frac{\bar{C}+a_{1}+a_{2}}{2}\right)^{\gamma_{2}-\gamma_{1}}
$$

Substituting in $v_{\mu}(W)$,

$$
\begin{gathered}
v_{\mu}(C)=\max _{\hat{c}^{1}, \hat{c}^{2}} \frac{\left(\hat{c}^{1}\right)^{1-\gamma_{1}}}{1-\gamma_{1}}+\left(\frac{\bar{C}+a_{1}+a_{2}}{2}\right)^{\gamma_{2}-\gamma_{1}} \frac{\left(\hat{c}^{2}\right)^{1-\gamma_{2}}}{1-\gamma_{2}} \\
\text { s.t. } \hat{c}^{1}+\hat{c}^{2}=W+a_{1}+a_{2} .
\end{gathered}
$$


Substituting the solution of (13), $\hat{c}^{1 *}$ and $\hat{c}^{2 *}$, in the individual utility functions and defining $\bar{c}=$ $\frac{\bar{C}+a_{1}+a_{2}}{2}, v_{\mu}(W)$ can be written in the form,

$$
v_{\mu}(W)=\frac{\left(\hat{c}^{1 *}\right)^{1-\gamma_{1}}}{1-\gamma_{1}}+(\bar{c})^{\gamma_{2}-\gamma_{1}} \frac{\left(\hat{c}^{2 *}\right)^{1-\gamma_{2}}}{1-\gamma_{2}} .
$$

Moreover, $\hat{c}^{1 *}$ and $\hat{c}^{2 *}$ must satisfy the budget constraint and the first order conditions, i.e.

$$
\begin{gathered}
\hat{c}^{1 *}+\hat{c}^{2 *}=W+a_{1}+a_{2} \text { for any } W \\
\left(\hat{c}^{1 *}\right)^{-\gamma_{1}}=(\bar{c})^{\gamma_{2}-\gamma_{1}}\left(\hat{c}^{2 *}\right)^{-\gamma_{2}} \text { for any } W .
\end{gathered}
$$

Differentiating both sides of (15) with respect to $W$,

$$
\frac{d \hat{c}^{1 *}}{d W}+\frac{d \hat{c}^{2 *}}{d W}=1
$$

Taking the logarithm of both sides of (16),

$$
-\gamma_{1} \ln \hat{c}^{1 *}=\left(\gamma_{2}-\gamma_{1}\right) \ln (\bar{c})-\gamma_{2} \ln \hat{c}^{2} .
$$

Differentiating with respect to $W$,

$$
-\gamma_{1} \frac{1}{\hat{c}^{1 *}} \frac{d \hat{c}^{1 *}}{d W}=-\gamma_{2} \frac{1}{\hat{c}^{2 *}} \frac{d \hat{c}^{2 *}}{d W}
$$

Solving (17) and (19) for $\frac{d \hat{c}^{1 *}}{d W}$ and $\frac{d \hat{c}^{2 *}}{d W}$,

$$
\begin{aligned}
\frac{d \hat{c}^{1 *}}{d W} & =\frac{\hat{c}^{1 *} \gamma_{2}}{\gamma_{1} \hat{c}^{2 *}+\gamma_{2} \hat{c}^{1 *}} \\
\frac{d \hat{c}^{2 *}}{d W} & =\frac{\hat{c}^{2 \hat{c}} \gamma_{1}}{\gamma_{1} \hat{c}^{2 *}+\gamma_{2} \hat{c}^{1 *}}
\end{aligned}
$$

Differentiating both sides of (14) with respect to $W$,

$$
v_{\mu}^{\prime}(W)=\left(\hat{c}^{1 *}\right)^{-\gamma_{1}} \frac{d \hat{c}^{1 *}}{d W}+(\bar{c})^{\gamma_{2}-\gamma_{1}}\left(\hat{c}^{2 *}\right)^{-\gamma_{2}} \frac{d \hat{c}^{2 *}}{d W} .
$$

Equation (16) implies,

$$
v_{\mu}^{\prime}(W)=\left(\hat{c}^{1 *}\right)^{-\gamma_{1}}\left(\frac{d \hat{c}^{1 *}}{d W}+\frac{d \hat{c}^{2 *}}{d W}\right)
$$

By relation (17),

$$
v_{\mu}^{\prime}(W)=\left(\hat{c}^{1 *}\right)^{-\gamma_{1}} .
$$

Differentiating (22) with respect to $W$,

$$
v_{\mu}^{\prime \prime}(W)=-\gamma_{1}\left(\hat{c}^{1 *}\right)^{-\gamma_{1}-1} \frac{d \hat{c}^{1 *}}{d W} .
$$


Substituting for $\frac{d \hat{c}^{1 *}}{d W}$,

$$
\begin{aligned}
v_{\mu}^{\prime \prime}(W) & =-\gamma_{1}\left(\hat{c}^{1 *}\right)^{-\gamma_{1}-1} \frac{\hat{c}^{1 *} \gamma_{2}}{\gamma_{1} \hat{c}^{2 *}+\gamma_{2} \hat{c}^{1 *}} \\
& =-\frac{\gamma_{1} \gamma_{2}}{\gamma_{1} \hat{c}^{2 *}+\gamma_{2} \hat{c}^{1 *}}\left(\hat{c}^{1 *}\right)^{-\gamma_{1}} \\
& =-\frac{\gamma_{1} \gamma_{2}}{\gamma_{1} \hat{c}^{2 *}+\gamma_{2} \hat{c}^{1 *}} v_{\mu}^{\prime}(W) .
\end{aligned}
$$

Differentiating (23) with respect to $W$,

$$
v_{\mu}^{\prime \prime \prime}(W)=\frac{\gamma_{1} \gamma_{2}}{\left(\gamma_{1} \hat{c}^{2 *}+\gamma_{2} \hat{c}^{1 *}\right)^{2}}\left(\gamma_{1} \frac{d \hat{c}^{2 *}}{d W}+\gamma_{2} \frac{d \hat{c}^{1 *}}{d W}\right) v_{\mu}^{\prime}-\frac{\gamma_{1} \gamma_{2}}{\gamma_{1} \hat{c}^{2 *}+\gamma_{2} \hat{c}^{1 *}} v_{\mu}^{\prime \prime} .
$$

By (17),

$$
v_{\mu}^{\prime \prime \prime}(W)=\frac{\gamma_{1} \gamma_{2}\left(\gamma_{1}-\gamma_{2}\right) \frac{d \hat{c}^{2 *}}{d W}+\gamma_{1}\left(\gamma_{2}\right)^{2}}{\left(\gamma_{1} \hat{c}^{2 *}+\gamma_{2} \hat{c}^{1 *}\right)^{2}} v_{\mu}^{\prime}-\frac{\gamma_{1} \gamma_{2}}{\gamma_{1} \hat{c}^{2 *}+\gamma_{2} \hat{c}^{1 *}} v_{\mu}^{\prime \prime} .
$$

Substituting for $\frac{d \hat{c}^{2 *}}{d W}$,

$$
v_{\mu}^{\prime \prime \prime}(W)=\frac{\gamma_{1} \gamma_{2}\left(\gamma_{1}-\gamma_{2}\right) \frac{\hat{c}^{2 *} \gamma_{1}}{\gamma_{1} \hat{c}^{2 *}+\gamma_{2} \hat{c}^{1 *}}+\gamma_{1}\left(\gamma_{2}\right)^{2}}{\left(\gamma_{1} \hat{c}^{2 *}+\gamma_{2} \hat{c}^{1 *}\right)^{2}} v_{\mu}^{\prime}-\frac{\gamma_{1} \gamma_{2}}{\gamma_{1} \hat{c}^{2 *}+\gamma_{2} \hat{c}^{1 *}} v_{\mu}^{\prime \prime} .
$$

Note that by (23),

$$
v_{\mu}^{\prime}(W)=-\frac{\gamma_{1} \hat{c}^{2 *}+\gamma_{2} \hat{c}^{1 *}}{\gamma_{1} \gamma_{2}} v_{\mu}^{\prime \prime}(W)
$$

Substituting in $v_{\mu}^{\prime \prime \prime}(W)$,

$$
\begin{aligned}
v_{\mu}^{\prime \prime \prime}(W) & =-\frac{\gamma_{1} \gamma_{2}\left(\gamma_{1}-\gamma_{2}\right) \frac{\hat{c}^{2 *} \gamma_{1}}{\gamma_{1} \hat{c}^{2 *}+\gamma_{2} \hat{c}^{1}}+\gamma_{1}\left(\gamma_{2}\right)^{2}}{\left(\gamma_{1} \hat{c}^{2 *}+\gamma_{2} \hat{c}^{1 *}\right)^{2}} \frac{\gamma_{1} \hat{c}^{2 *}+\gamma_{2} \hat{c}^{1 *}}{\gamma_{1} \gamma_{2}} v_{\mu}^{\prime \prime}-\frac{\gamma_{1} \gamma_{2}}{\gamma_{1} \hat{c}^{2 *}+\gamma_{2} \hat{c}^{1 *}} v_{\mu}^{\prime \prime} \\
& =-\frac{\left(\gamma_{1}-\gamma_{2}\right) \frac{\hat{c}^{2 *} \gamma_{1}}{\gamma_{1} \hat{c}^{2 *}+\gamma_{2} \hat{c}^{1 *}}+\gamma_{2}}{\gamma_{1} \hat{c}^{2 *}+\gamma_{2} \hat{c}^{1 *}} v_{\mu}^{\prime \prime}-\frac{\gamma_{1} \gamma_{2}}{\gamma_{1} \hat{c}^{2 *}+\gamma_{2} \hat{c}^{1 *}} v_{\mu}^{\prime \prime} \\
& =-\left[\gamma_{2}+\gamma_{1} \gamma_{2}+\frac{\left(\gamma_{1}-\gamma_{2}\right) \gamma_{1} \hat{c}^{2 *}}{\gamma_{1} \hat{c}^{2 *}+\gamma_{2} \hat{c}^{1 *}}\right] \frac{v_{\mu}^{\prime \prime}}{\gamma_{1} \hat{c}^{2 *}+\gamma_{2} \hat{c}^{1 *}} \\
& =-\left[\frac{\left(1+\gamma_{1}\right) \gamma_{2}}{\gamma_{1} \hat{c}^{2 *}+\gamma_{2} \hat{c}^{1 *}}+\frac{\left(\gamma_{1}-\gamma_{2}\right) \gamma_{1} \hat{c}^{2 *}}{\left(\gamma_{1} \hat{c}^{2 *}+\gamma_{2} \hat{c}^{1 *}\right)^{2}}\right] v_{\mu}^{\prime \prime} .
\end{aligned}
$$


Hence,

$$
\begin{aligned}
r_{\mu}(W) & =\frac{\gamma_{1} \gamma_{2}}{\gamma_{1} \hat{c}^{2 *}+\gamma_{2} \hat{c}^{1 *}}, \\
p_{\mu}(W) & =\frac{\left(1+\gamma_{1}\right) \gamma_{2}}{\gamma_{1} \hat{c}^{2 *}+\gamma_{2} \hat{c}^{1 *}}+\frac{\left(\gamma_{1}-\gamma_{2}\right) \gamma_{1} \hat{c}^{2 *}}{\left(\gamma_{1} \hat{c}^{2 *}+\gamma_{2} \hat{c}^{1 *}\right)^{2}} \\
& =\frac{1+\gamma_{1}}{\gamma_{1}} r_{\mu}(W)+\frac{\left(\gamma_{1}-\gamma_{2}\right) \hat{c}^{2 *}}{\gamma_{1}\left(\gamma_{2}\right)^{2}} r_{\mu}(W)^{2} .
\end{aligned}
$$

which concludes the proof.

It is now possible to prove theorem 2.

Proof. Differentiating both sides of (15) with respect to $\gamma_{2}$,

$$
\frac{d \hat{c}^{1 *}}{d \gamma_{2}}=-\frac{d \hat{c}^{2 *}}{d \gamma_{2}}
$$

Differentiating both sides of 18 with respect to $\gamma_{2}$,

$$
-\frac{\gamma_{1}}{\hat{c}^{1 *}} \frac{d \hat{c}^{1 *}}{d \gamma_{2}}=\ln (\bar{c})-\ln \hat{c}^{2 *}-\frac{\gamma_{2}}{\hat{c}^{2 *}} \frac{d \hat{c}^{2 *}}{d \gamma_{2}} .
$$

Solving for $\frac{d \hat{c}^{2 *}}{d \gamma_{2}}$ and using (24),

$$
\frac{d \hat{c}^{2 *}}{d \gamma_{2}}=-\frac{\hat{c}^{1 *} \hat{c}^{2 *} \ln \left(\frac{\hat{c}^{2 *}}{\bar{c}}\right)}{\gamma_{1} \hat{c}^{2 *}+\gamma_{2} \hat{c}^{1 *}} .
$$

Differentiating $r_{\mu}$ with respect to $\gamma_{2}$ and rearranging terms,

$$
\frac{\partial r_{\mu}}{\partial \gamma_{2}}=\frac{\left(\gamma_{1}\right)^{2} \hat{c}^{2 *}+\gamma_{1} \gamma_{2}\left(\gamma_{2}-\gamma_{1}\right) \frac{d \hat{c}^{2 *}}{d \gamma_{2}}}{\left(\gamma_{1} \hat{c}^{2 *}+\gamma_{2} \hat{c}^{1 *}\right)^{2}}
$$

Let $\theta=\frac{\gamma_{2}}{\gamma_{1}}<1$. Substituting for $\frac{d \hat{c}^{2 *}}{d \gamma_{2}}$,

$$
\frac{\partial r_{\mu}}{\partial \gamma_{2}}=\frac{\theta \hat{c}^{1 *} \hat{c}^{2 *}+\left(\hat{c}^{2 *}\right)^{2}+\theta(1-\theta) \hat{c}^{1 *} \hat{c}^{2 *} \ln \left(\hat{c}^{2 *} / \bar{c}\right)}{\left(\hat{c}^{2 *}+\theta \hat{c}^{1 *}\right)^{3}}
$$

By the Inada condition, $\hat{c}^{1 *}>0$ and $\hat{c}^{2 *}>0$. Consequently the denominator of (26) is strictly positive and the numerator is negative if and only if,

$$
\theta+\hat{c}^{2 *} / \hat{c}^{1 *}+\theta(1-\theta) \ln \left(\hat{c}^{2 *} / \bar{c}\right)<0 .
$$

By (16), $\hat{c}^{1 *}=(\bar{c})^{1-\theta}\left(\hat{c}^{2 *}\right)^{\theta}$. Hence (27) can be written in the form,

$$
\theta+\left(\hat{c}^{2 *} / \bar{c}\right)^{1-\theta}<\theta(1-\theta)\left(\hat{c}^{2 *} / \bar{c}\right) .
$$

Let $\bar{c}^{2 *}=\hat{c}^{2 *} / \bar{c}$ and define $f\left(\bar{c}^{2 *}\right)=\theta+\left(\bar{c}^{2 *}\right)^{1-\theta}$ and $g\left(\bar{c}^{2 *}\right)=\theta(1-\theta)\left(-\ln \bar{c}^{2 *}\right)$. Then $f\left(\bar{c}^{2 *}\right)$ and $g\left(\bar{c}^{2 *}\right)$ satisfy the following conditions: 
- $f\left(\bar{c}^{2 *}\right)$ is continuous with respect to $\bar{c}^{2 *}$;

- $f^{\prime}\left(\bar{c}^{2 *}\right)=\theta+(1-\theta)\left(\bar{c}^{2 *}\right)^{-\theta}>0$ by $0<\theta<1$;

- $\lim _{\bar{c}^{2 *} \downarrow 0} f\left(\bar{c}^{2 *}\right)=\theta<1$;

- $\lim _{\bar{c}^{2 *} 1} f\left(\bar{c}^{2 *}\right)=\theta+1>1$;

- $g\left(\bar{c}^{2 *}\right)$ is continuous with respect to $\bar{c}^{2 *}$;

- $g^{\prime}\left(\bar{c}^{2 *}\right)=-\frac{\theta(1-\theta)}{\bar{c}^{2 *}}<0$ by $\theta<1$;

- $\lim _{\bar{c}^{2 *} \downarrow 0} g\left(\bar{c}^{2 *}\right)=\infty$;

- $\lim _{\bar{c}^{2 *} 1} g\left(\bar{c}^{2 *}\right)=0$.

This implies that there exists a $\check{c}>0$ such that (28) is satisfied for all $\hat{c}^{2 *}<\check{c}$. Under the assumptions of section 5, $\hat{c}^{2 *}$ is a continuous function of $W$. As a consequence there exists a $\hat{W}>0$ such that (28) is satisfied for all $W<\hat{W}$. Hence,

$$
\frac{\partial r_{\mu}}{\partial \gamma_{2}}<0 \text { for any } W \in[0, \hat{W}) .
$$

The inequality for household relative risk aversion follows directly.

By lemma 5,

$$
p_{\mu}=\frac{\gamma_{1}+1}{\gamma_{1}} r_{\mu}+\frac{\left(\gamma_{1}-\gamma_{2}\right) \hat{c}^{2 *}}{\gamma_{1}\left(\gamma_{2}\right)^{2}}\left(r_{\mu}\right)^{2} .
$$

Differentiating with respect to $\gamma_{2}$,

$$
\begin{aligned}
\frac{\partial p_{\mu}}{\partial \gamma_{2}} & =\left(\frac{\gamma_{1}+1}{\gamma_{1}}+\frac{2\left(\gamma_{1}-\gamma_{2}\right) \hat{c}^{2 *}}{\gamma_{1}\left(\gamma_{2}\right)^{2}} r_{\mu}\right) \frac{\partial r_{\mu}}{\partial \gamma_{2}}-\left(\frac{\gamma_{2}+2\left(\gamma_{1}-\gamma_{2}\right)}{\gamma_{1}\left(\gamma_{2}\right)^{3}}\right) \hat{c}^{2 *}\left(r_{\mu}\right)^{2} \\
& +\frac{\left(\gamma_{1}-\gamma_{2}\right)}{\gamma_{1}\left(\gamma_{2}\right)^{2}}\left(r_{\mu}\right)^{2} \frac{d \hat{c}^{2 *}}{d \gamma_{2}} .
\end{aligned}
$$

Note that $\frac{\partial r_{\mu}}{\partial \gamma_{2}}$ can be written as follows:

$$
\frac{\partial r_{\mu}}{\partial \gamma_{2}}=\frac{\hat{c}^{2 *}\left(r_{\mu}\right)^{2}}{\left(\gamma_{2}\right)^{2}}-\frac{\left(\gamma_{1}-\gamma_{2}\right)}{\gamma_{1} \gamma_{2}}\left(r_{\mu}\right)^{2} \frac{d \hat{c}^{2 *}}{d \gamma_{2}}
$$

which implies,

$$
\frac{\left(\gamma_{1}-\gamma_{2}\right)}{\gamma_{1}\left(\gamma_{2}\right)^{2}}\left(r_{\mu}\right)^{2} \frac{d \hat{c}^{2 *}}{d \gamma_{2}}=\frac{\hat{c}^{2 *}\left(r_{\mu}\right)^{2}}{\left(\gamma_{2}\right)^{3}}-\frac{1}{\gamma_{2}} \frac{\partial r_{\mu}}{\partial \gamma_{2}} .
$$


Substituting for $\frac{d \hat{c}^{2 *}}{d \gamma_{2}}$ in (30) and rearranging terms,

$$
\frac{\partial p_{\mu}}{\partial \gamma_{2}}=\left(\frac{\gamma_{2}+\gamma_{2} \gamma_{1}-\gamma_{1}}{\gamma_{2} \gamma_{1}}+\frac{2\left(\gamma_{1}-\gamma_{2}\right) \hat{c}^{2 *}}{\gamma_{1}\left(\gamma_{2}\right)^{2}} r_{\mu}\right) \frac{\partial r_{\mu}}{\partial \gamma_{2}}-\frac{\gamma_{1}-\gamma_{2}}{\gamma_{1}\left(\gamma_{2}\right)^{3}} \hat{c}^{2 *}\left(r_{\mu}\right)^{2}
$$

By $\gamma_{1}>\gamma_{2}$, the second term on the RHS is always negative. Moreover by $\gamma_{1}>\gamma_{2} \geq 1$, the sign of the first term on the RHS is equivalent to the sign of $\frac{\partial r_{\mu}}{\partial \gamma_{2}}$. By (29), this implies,

$$
\frac{\partial p_{\mu}}{\partial \gamma_{2}}<0 \text { for any } W \in[0, \hat{W})
$$

where $\hat{W}$ is the bound defined for household risk aversion. The inequality for household relative prudence follows directly. This concludes the proof. 